\title{
Synthesis and Characterization of Abacavir Acetic Acid Salt Polymorphic Transition from Abacavir Free Base by Using Process Analytical Tools (PAT)
}

\author{
Veeraswamy Rama1, Nagaraju Rajana ${ }^{2}$, K. Sateesh Reddy², Siddaiah Vidavulur ${ }^{1}$, T.V. Pratap ${ }^{1}$, \\ Siva Bandi ${ }^{3}$, Rohini Rondla4, M. Radhika ${ }^{5}$, K. Bhaskar ${ }^{4}$ and P. Muralidhar Reddy ${ }^{4}$ \\ ${ }^{1}$ Department of Organic Chemistry and FDW, Andhra University, Visakhapatnam (AP) \\ ${ }^{2}$ Technology Development Center, Custom Pharmaceutical Services, Dr. Reddy's Laboratories Ltd, Hyderabad \\ ${ }^{3}$ Laboratory for Bioanalytical Chemistry, Institute of Chemistry, University of Neuchatel, Avenue de Bellevaux \\ 51, CH-2000 Neuchatel, Switzerland \\ ${ }^{4}$ Department of Chemistry, University College of Science, Osmania University, Hyderabad, Telangana \\ ${ }^{5}$ Department of Chemistry, Nizam College, Osmania University, Hyderabad, Telangana, India.
}

\begin{abstract}
Abacavir $(\mathrm{ABC})$ is a guanosine analogueusedto prevent and treat HIV/AIDS.It is a neucleoside reverse transcriptase inhibitor that inhibits viral replication and it is marketed as hemisulphate salt and with combination of lamivudin/ zidovudin.Nevertheless, Abacavir succinic acid, malonic acid, sulfuric acid and $\mathrm{HCl}$ salts are mentioned in the literature. The novel acetic acid salt from Abacavir is mentioned here. In this study, we used Focused Beam Reluctant Measurement (FBRM) and Particle Vision Microscope (PVM) PAT tools to track the polymorphic transition from Abacavir free base to acetic acid salt, which is characterized by DSC, PXRD, FTIR, and 1HNMR to confirm the structure.
\end{abstract}

KEY WORDS: PROCESS ANALYTICAL TOOLS, ABACAVIR, POLYMORPH, ACETIC ACID SALT.

\section{INTRODUCTION}

Process Analytical Technology (PAT) is defined as "a system for designing, analyzing and controlling output through timely measurements (i.e., during processing) of the critical quality and performance attributes of raw and in-process materials and processes, to ensure the quality of the finished product." Measurements of Process Analytical Technology (PAT) may consist

\section{ARTICLE INFORMATION}

Received 1st Nov 2020 Accepted after revision 15th Dec 2020 Print ISSN: 0974-6455 Online ISSN: 2321-4007 CODEN: BBRCBA

Thomson Reuters ISI Web of Science Clarivate Analytics USA and Crossref Indexed Journal

\section{Clarivate
Analytics}

NAAS Journal Score 2020 (4.31)

A Society of Science and Nature Publication,

Bhopal India 2020. All rights reserved.

Online Contents Available at: http//www.bbrc.in/

Doi: http://dx.doi.org/10.21786/bbrc/13.15/36 of intermediates, raw materials, products. These measurements can give valuable data for understanding how process variables affect the chemistry, bioprocess, and particle-based systems (Thumar et al., 2012).These tools include focused beamreflectance measurement (FBRM) (Sullivan et al., 2003), particle video microscope (PVM), Raman spectroscopy(Sullivan et al., 2005 and (Ono et al., 2004)). Fourier transform infrared spectroscopy (FTIR)(Wang et al., 2000, Liotta and Vijay 2004) near infrared spectroscopy (NIR) (Pollanen et al.,2005,Smetet al., 2005, Moes et al., 2008) etc,.

The application of these apparatus can give instant information about the process. By using these online tools we can save the time cost and repetition of experimentation. FBRM is probe based, in process tool used to monitor the chord counts and chord length distribution of particle in a crystallization mass, due to change in the particle size and shape, the chord length

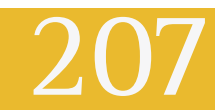


distribution will vary, based on this the user can identify the polymorph transition of the substance (Sullivan et al., 2003). It is also used to determine the solubility and metastable zone width of substance in particular solvents, it is also useful tool in formulation dissolution studies (Spong et al., 2004 and Long et al., 2009) and Polymorphic transformation is often accompanied by a change in crystal habit. PVM is probe based video microscope which captures the images of the crystals as they actuallyexist in the process at full process concentration. It shows distinct change in morphology of one polymorph to other. FBRM and PVM combination is powerful tool for quickly and easily characterizing polymorph and pseudo polymorphic transitions in the case where there is change in crystal habit.

In pharmaceutical industry, crystallization and isolation of suitable and stable polymorph for formulation development is very important aspect (Sullivan et al., 2003) andthe bioavailability studies are depending on the polymorph, and further the selected solid form should meet the basic requirements of optimalstability, reproducibility and scalability which will eventually lead to devise a robust and reliable process for its manufacture. The existence of more than one crystal structure for a chemical substance is referred as polymorphism.The importance of polymorph screeningcan be visualized by a fact of sudden appearance or disappearance of a polymorphic form during manufacturing and storage (Yu et al., 2004),Such changes can lead to a variety of significant implications in terms of the patient safety, financing and brand image of company and so on.These polymorph transitions will be monitored with the help of online process analytical tools like FBRM, PVM and Raman spectroscopy etc.

The effect of parameters like temperature,agitation, coolingrate, seed point and seed quality, relative humidity, $\mathrm{pH}$, solubility etc. willaffect the polymorph conversion/ isolation of stable form. Regulatory authorities have established several guidelines and strategies to integrate series of process analytical tools as well as analytical methods to understand polymorphism in solvate hydrate, and anhydrate types of a drug (Rathore et al., 2010) PXRD (Powder X-Ray Diffraction) regarded as the standard technique that provide polymorphism fingerprint details.Additional perspectives on polymorphism can be provided by various techniques such as thermal (DSC, TGA), spectroscopy (Raman, Near-Infrared and, Infrared). There are several in-silico instruments which, by predicting the stable polymorphs of compounds, reduce the experimental load. This ensures that problems are expected and the necessary parameters are recommended to stabilise the solid form discovered.It is notable that the task of form selection is not just for easy unit operation, it is an important aspect process of drug production.To date Abacavir succinic acid (Daluge et al., 1995)malonic acid (Narasimha R et al., 2010), sulfuric acid (Renu. Cet al., 2011) and $\mathrm{HCl}$ salts (Singh G P et al., 2015) are mentioned in the literature. In this study novel acetic acid salt from Abacavir is identified.

\section{MATERIAL AND METHODS}

2.1. General: All experiments were run in a automated reactor consists cryostat and Abacavir freebase compound gifted by Dr.reddy's laboratories, reagents and solvents were purchased from commercial sources. In situ data were acquired using a FBRM (4.4 version IC software) and PVM (Standard Vseries software) from Mettler Toledo AutoChem (Columbia, SC, USA).

2.2. Instrumental Conditions: Lasentec FBRM (Models G400 by Mettler Toledo AutoChem, Columbia, MD) was used to determine the distribution profiles of chord length or to screen for the existence of crystals or solid species during operation. An in-process video microscope (Model 819 by Mettler Toledo AutoChem, Columbia, $\mathrm{MD}$ ) was used during the processes to capture the inline morphology of crystals or solid species, particularly crystallization ones. For offline analysis PXRD, DSC, TGA and FT-IR data was used to assess the polymorphic transition.

2.2.1. Differential Scanning Calorimetry (DSC): Samples were subjected for DSC analysis on TA (Thermal Advantage) instrument with the heating of compound at a rate of $10{ }^{\circ} \mathrm{C} / \mathrm{min}$ up to $200^{\circ} \mathrm{C}$ with the constantdry nitrogen gas purging with rate of $20 \mathrm{~mL} / \mathrm{min}$.

2.2.2. Thermogravimetry Analysis (TGA): Samples were subjected to TGA Thermograms on a Thermal Advantage (TA) Q 500 series machine by heating the samples at a rate of $10{ }^{\circ} \mathrm{C} / \mathrm{min}$ up to $300{ }^{\circ} \mathrm{C}$ with the purging of dry nitrogen gas [Balance $(40 \mathrm{~mL} / \mathrm{min})$ and Furnace $(60 \mathrm{~mL} /$ min)].

2.2.3. Powder X-Ray Diffraction (PXRD): X-ray powder diffraction data were collected on a PAN analytical X'Pert PRO diffractometer (X'cellerator detector, $\mathrm{Cu}$-anode, $45 \mathrm{KV}, 40 \mathrm{ma}$, Brag-Brentano geometry) using the $2 \theta$ scan range, step size, and exposure time of $3-40^{\circ}, 0.03^{\circ}$ and 1200 s/step respectively.

2.2.4. FT-IR Spectroscopy: In the mid-IR (4000-400 $\mathrm{cm}-1$ ), FTIR spectra of Abacavir free base and Abacavir acetic acid salt were measured using the Cary 680 FTIR spectrometer (Agilent, Santa Clara, CA) coupled with a $30-200{ }^{\circ} \mathrm{C}$ room temperature detector range with a $20^{\circ} \mathrm{C}$ step. $4 \mathrm{~cm}-1$ spectral resolutions, 16 scans, were the data collection parameters. The ATR system was preheated to the appropriate temperature, and then the sample was placed and the spectrum was measured.

2.3. Experimental Procedure of $A B C$ Acetic Acid Salt: $A B C$ acetic acid salt was obtained by suspending $12 \mathrm{~g}$ of $A B C$ Form-1 in mixture of $360 \mathrm{~mL}$ of di isopropyl ether and $3.6 \mathrm{~mL}$ acetic acid in $500 \mathrm{ml}$ glass reactor, inserted FBRM and PVM, in to the 1 liter reactor, the reaction mixture was maintained for about 4 to 6 hours at 15-25 ${ }^{\circ} \mathrm{C}$, followed by filtration and drying. Obtained as needle shape crystals was characterized using 


\section{RESULTS AND DISCUSSION}

\subsection{Monitoring of Abacavir free Base to Acetic Acid Salt Using Online Analysis}

3.1.1. FBRM AND PVM: In this study we have monitored the polymorph conversion of Abacavir free base to acetic acid salt (Figure 1) with help of Focused beam refluctant measurement (FBRM) and Particle vision microscope (PVM).

Figure 1: Chemical structure of Abacavir free base and acetic acid salt

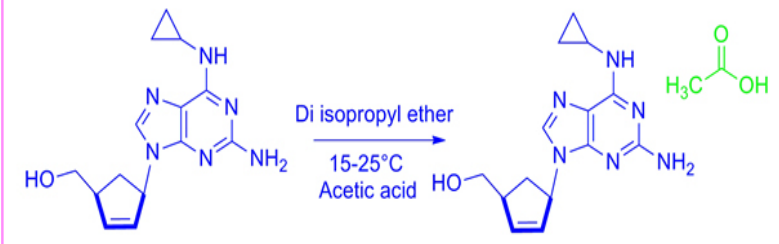

Abacavir free base

Abacavir acetic acid salt

By using these process analytical tools we can avoid the offline sample analysis which is time consuming process. We have identified the novel polymorph of $A B C$ acetic acid salt and the polymorph transition from Form-1 to salt was monitored using FBRM and PVM. It was clearly indicating the polymorph transition by change in chord length distribution and increase in countsdue to variation in the particle size and morphology upon stirring with time, particle shape change from plate type crystals to needle shape crystal was monitored by using particle video microscope. The change in particle count and crystal shape indicates that the free base converted to acetic acid salt, same was analyzed using DSC, TGA PXRD and FT-IR.

Figure 2: FBRM Chord length distribution of the Polymorph transformation (No weight \#sec)

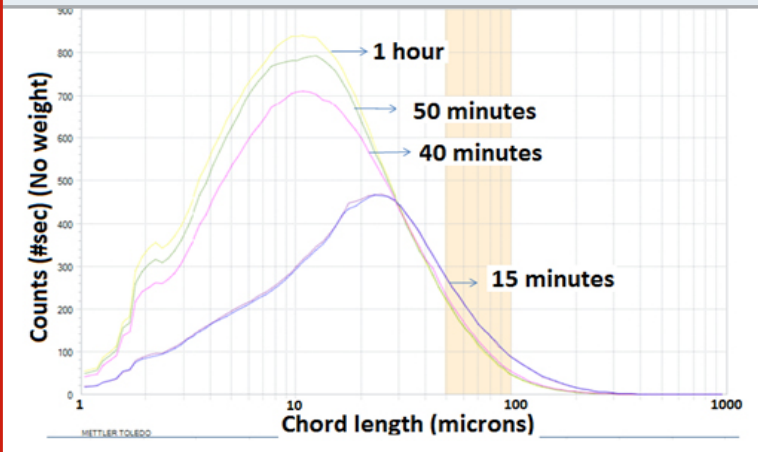

The transition from Abacavir form- 1 to acetic acid salt was clearly indicating in Figure 2At 15 minutes chord length distribution shows the coarser particles of $A B C$ free basewhereas the distribution of 40 minutes converted to acetic acid salt which shows finer particles, further completely converted to finer side in 50 minutesand $1 \mathrm{hr}$ respectivelyalso there was a change in particle count is clear agreement for complete conversion of free base to salt.

Figure 3(a): PVM image at 15 minutes of crystallization

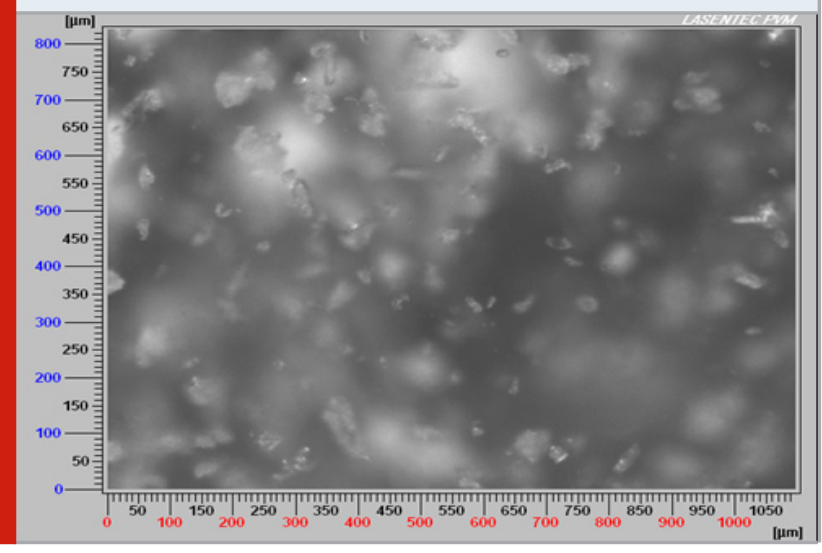

Figure 3(b): PVM image at 25 minutes of crystallization in transition phase

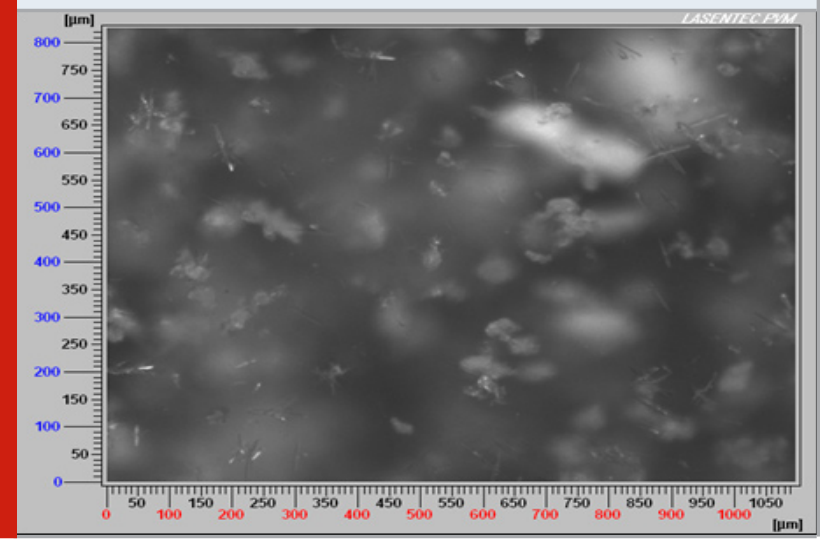

Similarly PVM provides clear evidence of the transition from Abacavir free base, the crystal shape is plate type crystal shows in figure (3a) is corresponding to Abacavir free base upon stirring, after 30 minutes in figure (3b) shows the needle shape crystals formation which indicates the conversion of Acetic acid salt and after 60 minutes in figure (3c) was completely converted to Acetic acid salt of Needle shape crystals. It is the good evidence for the conversion of acetic acid salt.

\subsection{Monitoring Of Abacavir Free Base To Acetic Acid Salt Using Offline Analysis.}

3.2.1. Thermal Analysis (DSC AND TGA): Differential scanning calorimetry is measures the energy absorbed(endotherm) or produced (Exotherm) as afunction of time or temperature. It is used to characterize melting,crystallization,loss of solvents, other process involving an energy change. Differential scanning calorimetry may also applied to process involving a change in heat capacity,such as the glass transition,Providing direct details on thermodynamic parameters associated with the crystalline/amorphous process, including the ease, simplicity and speed of the 
calculation. ABC Form-1 heating in DSC results in a sharp endothermic peak of $156.19{ }^{\circ} \mathrm{C}$ with an onset of $154.81^{\circ} \mathrm{C}$. This endotherm is the melting event for a $\Delta \mathrm{H}=$ $165.31 \mathrm{~J} / \mathrm{g}$ and there was no sign of any phase transition before melting (Figure 4).In the same way heating of $\mathrm{ABC}$ acetic acid salt results sharp endotherm peak at $103.57^{\circ} \mathrm{C}$ with an onset at $99.17^{\circ} \mathrm{C}$.

Figure 4: DSC thermogram overlay of $\mathrm{ABC}$ Acetic acid and free base.

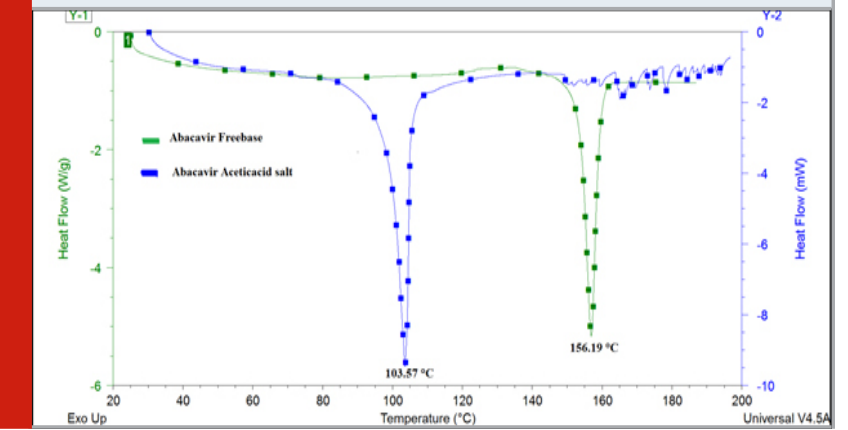

In thermo gravimetric analysissample is heated in presence of inert atmosphere at controlled rate. The change in the weight of the substance is recorded as a function of temperature or time. The temperature is increased at a constant rate for a known sample and the changes in weights are recorded as function of temperature at different interval. Abacavir acetic acid salt was subjected for thermo gravimetric analysis, weight loss is $0.782 \% \mathrm{w} / \mathrm{w}$ which is corresponding to melting and do not show any residual solvate. TGA thermogramsof ABC acetic acid shown in Figure 5.

Figure 5: TGA thermogram of ABC Acetic acid

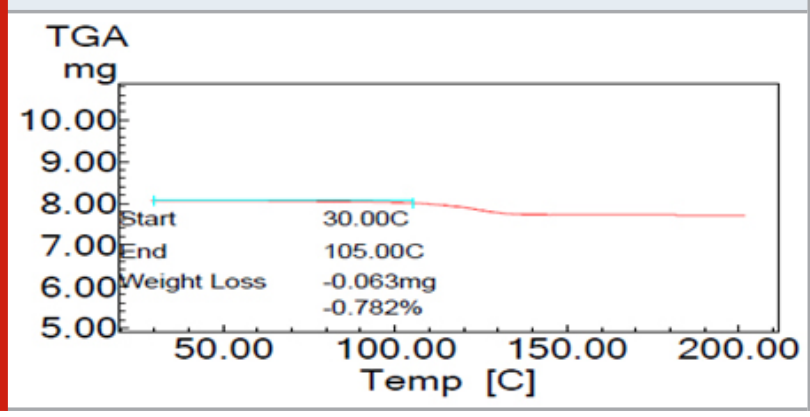

3.2.2. Pxrdanalysis: Powder XRD is a non-destructive technique and it gives a unique powder pattern for each solid materials. Powder XRD has gained a important role in the pharmaceutical industry in identifying various solid forms of active pharmaceutical ingredients and also in identifying the crystallinity of materials. The changes in the resulted powder pattern when compared to the starting materials indicate the novel solid form. The characteristics peak of Abacavir free base was observed at $2 \theta 7.97,10.00,10.19,10.60,14.98,16.02,16.54,19.46$, $20.13,23.00,24.97$, and 27.15. Whereas Abacavir acetic acid salt shows $2 \theta 7.31,10.61,14.70,19.25,25.00,25.91$, 26.96 and 29.89 . The appearance of new peaks indicates that the formation of new solid form i.e. Acetic acid salt shown in figure 6.

Figure 6: PXRD histogram overlay of $A B C$ free base and ABC Acetic acid

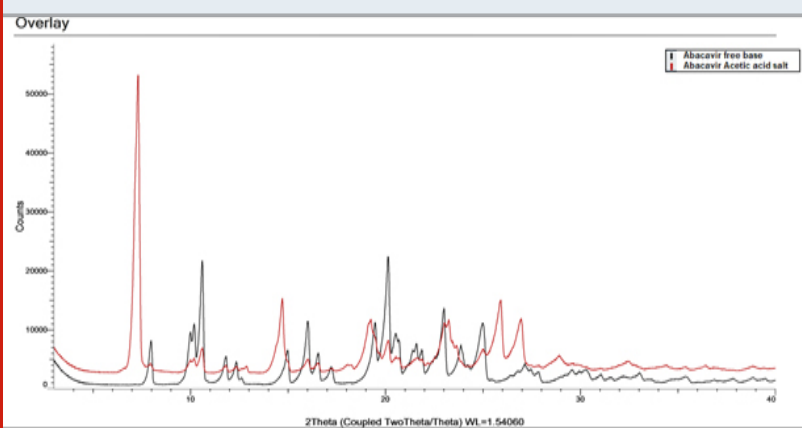

Table 1. Stretching and bending frequencies of Abacavir free base and Abacavir acetic acid salt.

\begin{tabular}{|c|c|c|c|c|c|c|}
\hline S.No & Compound & $\begin{array}{c}\text { Acid } \\
\mathrm{C=0} \\
\left(\mathrm{cm}^{-1}\right)\end{array}$ & $\begin{array}{c}\text { Acid } \\
\mathrm{OH} \\
\left(\mathrm{cm}^{-1}\right)\end{array}$ & $\begin{array}{c}\text { Alcohol } \\
\mathrm{OH} \\
\left(\mathrm{cm}^{-1}\right)\end{array}$ & $\begin{array}{c}\mathrm{N}-\mathrm{H} \\
\text { stretch } \\
\text { OH }\left(\mathbf{c m}^{-1}\right)\end{array}$ & $\begin{array}{c}\mathrm{N}-\mathrm{H} \\
\text { Bending } \\
\left(\mathrm{cm}^{-1}\right)\end{array}$ \\
\hline 1 & $\begin{array}{c}\text { Abacavir } \\
\text { free base }\end{array}$ & - & - & 3357 & 3310 & 1609 \\
\hline 2 & $\begin{array}{c}\text { Abacavir } \\
\text { acetic acid } \\
\text { salt }\end{array}$ & 1031 & 3423 & 3012 & 3125 & 1610 \\
\hline
\end{tabular}

Figure 7: FT-IR spectrum overlay of $A B C$ free base and ABC Acetic acid

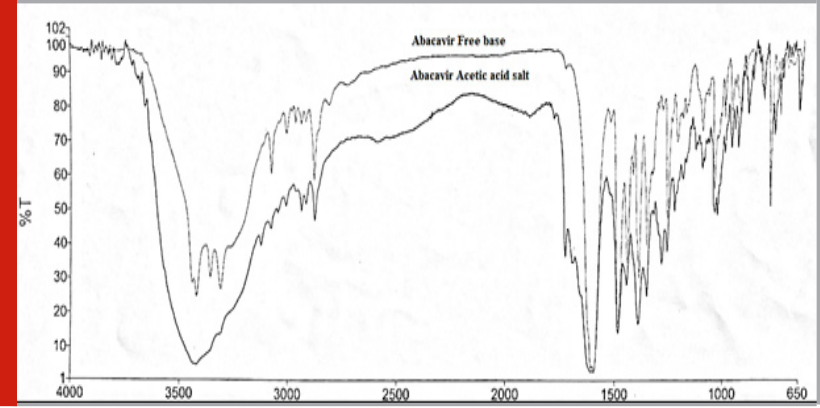

3.2.3. FT-IR Analysis: The change in FT-IR stretching values resulted in new solid form i.e., Abacavir acetic acid salt.Acid $\mathrm{C}=0$ stretching value observed at $1031 \mathrm{~cm}-1$ and acid $\mathrm{OH}$ stretching peak observed at $3423 \mathrm{~cm}-1$ the same were captured in Table 1. FT-IR spectra were shown in Figure 7.

3.2.4. H1NMR: H1NMR of Abacavir acetic acid is showing acetic acid proton at $\delta 11.94 \mathrm{ppm}$, which is good evidence for the formation of acetic acid salt.NMR spectra were shown in Figure 8.

3.2.5. Solubility Study: Solubility was performed in plain distilled water at $25{ }^{\circ} \mathrm{C}$. Abacavir free base shows 1.3 $\mathrm{mg} / \mathrm{mL}$, Abacavir sulfate shows $78 \mathrm{mg} / \mathrm{mL}$ solubility, 
whereas Abacavir acetic acid salt shows $158 \mathrm{mg} / \mathrm{mL}$ which is highly soluble in water.

Figure 8: NMR spectra of ABC Acetic acid

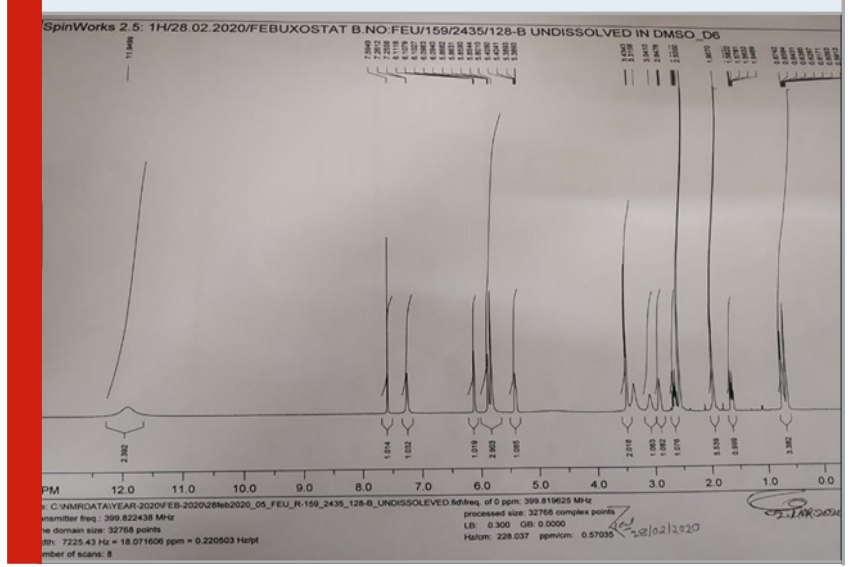

\section{CONCLUSION}

In pharmaceuticals, polymorphism is a very essential characteristic, as it will rely on the polymorph's bioavailability and stability. The development of an acceptable form is a challenging work. The polymorphic conversion and stability of the particular polymorph will be influenced by various process parameters. As per literature $A B C$ free base have four crystallinesalt polymorphs reported. During the screening study we have identified that transition of $A B C$ free base from Form-1 to Abacavir acetate salt. It was demonstrated in multigram scale and polymorph was characterized using FBRM, PVM, DSC,TGA, PXRD and FT-IR.

\section{ACKNOWLEDGEMENTS}

The authors thanks to Dr. Reddy's Laboratories for continued support.DRL IPD communication no: IPDO IPM-00651.The authors' (PMR and KB) thanks to UGC for Start-up grant, UGC-UPE FAR \&t DST-PURSE PROGRAMME (2017-21) Osmania University, Hyderabad for financial support.

Conflict of Interest: The authors declare that there is no conflict of interests regarding the publication of this article.

\section{REFERENCES}

Daluge, Susan, Mary Chapel Hill, Wilson, Jeffrey, Douglas Durham. (1995). European patent application no EP 0777669 B1

Horvath A., Smet K.D., Ormerod D., Depre D., Balado C.P., Govaerts T., Schorpion H. (2005). Development of the one-carbon homologation of a 4-methyl coumarin assisted by in-line FTIR. Org. Process Res.Dev. 9(3); 356-359.

Liotta V., Vijay S. (2004). Monitoring and feedback control of supersaturation using ATR-FTIR to produce an active pharmaceutical ingredient of a desired crystal size. Org. Process. Res. Dev. 8(3); 488-494.
Long M., Chen Y. (2009). Developing solid oral dosage forms: pharmaceutical theory \& practice; Academic press. $319-340$

Mettler-Toledo (2010) Auto Chem, 7075 Samuel Morse Drive, Columbia, MD, U.S.A. 2010

Moes J.J., Rujiken M.M., Gout E., Henderik W., Frijlink, M. (2008 Application of process analytical technology in tablet process development using NIR spectroscopy: Blend uniformity, content uniformity and coating thickness measurements. International journal of pharmaceutics.357(1);108-118

Narasimha R., Kaushik V K., Aminul I. (2010).European patent application no EP 2305680 A2

Ono T., Horst J.H., Jansens P.J. (2004). Quantitative measurement of polymorphic transformation of LGlutamic acid using In-situ Raman spectroscopy. Crystal Growth \&t Design, 4(3); 465-469

Pollanen K., Hakkinen A., Reinikainen S., Rantanen J., Karjalainen M., Kultanen M.L., Nystrom L. (2005). IR spectroscopy together with multivariate data analysis as a process analytical tool for in-line monitoring of crystallization process and solid-state analysis of crystalline product.J.Pharm. Biomed Anal. 38(2); 275284

Rathore A.S., Bhambure R., Ghare V. (2010). Process analytical technology (PAT) for biopharmaceutical products. Analytical and bioanalytical chemistry 398; 137-154

Renu. C., Poonam A., Anupam S., Somnath C., Jain D.V.S. (2011). J Pharm Educ Res Vol. 2, Issue No. 2.

Singh G P., Srivastava D. (2015) WIPO patent application no W0 2015/049623 A1.

Smet K.D., Van Dun J., Stokbroekx B., Spittaels T., Schroyen, C., Van Broeck P., Lambrechts J., Van Cleuvenbergen D., Smout G., Dubois J., Horvath A., Verbraeken J., Cuypers J. (2005). Selectivity control by use of Near-IR for a hydrogenation process.Org. Process Res.Dev. 9(3); 344-347.

Spong R., Price, C. P., Jayasankar, A., Matzger, A. J., Rodriguez-Hornedo N. (2004). General principles of pharmaceutical solid polymorphism: A super molecular perspective. Adv. Drug Delivery. Rev. 56 (3); 241-274 Sullivan B., Barrett P., Hsiao G., Carr A., Glennon B. (2003). In Situ Monitoring of Polymorphic Transitions. Org.Process Res. Dev. 7(6); 977-982.

Sullivan B., Glennon B. (2005). Application of in Situ FBRM and ATR-FTIR to the Monitoring of the Polymorphic Transformation of D-Mannitol.0rg. Process Res.Dev. 9(6); 884-889.

Thumar R. V., Kalola, V. N., Nadpara, N. P., Patel, P. B. (2012).A complete review of process analytical technology. International Journal of Pharmaceutical Sciences Review and Research. 17(1); 57-65.

Wang F., Wachter J.A., Frederick J., Berglund K.A. (2000). An investigation of solvent-mediated polymorphic transformation of progesterone using in situ Raman spectroscopy.Org. Process Res.Dev. 4 (5); 391-395.

Yu L., Lionberger R.A., Raw A.S., Costa R.D., Wu H., Hussain A.S. (2004). Application of Process Analytical technology to crystallization process. Advanced drug delivery reviews 56(3); 349-369 